\title{
The Evaluation of ITSM Open Source Software for Small Medium Organizations Based on ITIL v.3 Criteria using AHP Method
}

\author{
Husni Teja Sukmana ${ }^{1}$, Luh Kesuma Wardhani ${ }^{2}$, \\ Roni Argantone ${ }^{3}$ and KyungOh Lee ${ }^{4}$ \\ ${ }^{1,2,3}$ Informatics Department Faculty of Science and Technology \\ UIN Syarif Hidayatullah Jakarta, Indonesia \\ ${ }^{4}$ Computer Engineering, Sunmoon University, Korea \\ husniteja@uinjkt.ac.id,luhkesuma@uinjkt.ac.id, \\ roniargantone@mhs.uinjkt.ac.id,leeko@sunmoon.ac.kr
}

\begin{abstract}
Information Technology Service Management (ITSM) is a framework that emphasizes Information Technology (IT) services to generate value for its customers. ITSM can be applied in large, medium and even small scale organization. On the small organizations or new in implementing ITSM, the use of open source software can be a solution in implementing ITSM. The problem is the lack of guidance in the selection of ITSM open source software for those organizations. In this study we looked for appropriate criteria to guide the selection of ITSM open source software and found that Service Operation on ITSM should be a criterion in the selection. We tested the criteria using Analytic Hierarchy Process (AHP) approach. Three ITSM software used in this evaluation, there are iTop, OTRS and Idoit. The results of those three-software tested using the AHP show that iTop is a top priority for the organization to start the ITSM implementation journey. iTop has a higher global priority value: 0.68, where the OTRS 0.17, and IDOIT 0.15.
\end{abstract}

Keywords: ITSM, Open Source Software, ITIL v.3, Service Operation, AHP

\section{Introduction}

Nowadays, the competition among organizations to be able to survive is highly competitive. No exception for organizations that provide IT-based services. In order to win the competition, each IT organization tries to provide a service that can generate beneficial "value" for the customers, with the hope that value can maintain customer loyalty to the organization, which is ultimately the values have positive impact by the increase in business revenue of the organization.

In order to make services to generate value, an organization should adopt a framework of IT Service Management (ITSM). Some frameworks are already available, among other, include: ITIL v.2, ITIL v.3, ISO 20000-1, COBIT 4.0, C 5.0, CMMI-SVC, MOF 4.0 and ITUP [1]. Based on the creator, these frameworks can be divided into two, first made by the vendor, among others includes: MOF 4.1 (Microsoft), ITUP (IBM). Second, it is created by organization and community, among others includes ITIL pioneered by ITSM forum (ITSMF), CMMI-SVC by the Software Engineering Institute (SEI), COBIT from ISACA and the International Organization for Standardization (ISO) published the standards related to ITSM such as ISO 20000-1,

In fact, from the above frameworks, the IT Infrastructure Library (ITIL) is most widely used and implemented by the organizations [2], [3] , [4]. Currently the ITIL version used is ITIL v.3. To make a good service, there are five major processes in ITIL v.3, those are: Service Strategy, Service Design, Service Transition, Service Operation and Continual Service Improvement. Each main process will be supported by some other processes, for 
example in service operation there are five sub-processes, include: Event management, incident management, request management, problem management, and access management.

To support the implementation of ITSM in an organization, some software has been launched both paid software and open source software. Some paid software as described by Gartner [5] among others, includes: Cherwell Software, Samanage, Service Now and BMC Software. In addition to paid software, many companies and communities also attempt to create ITSM open source software, among others, includes: Combodo iTop, OTRS: ITSM, CITSMART, Project Open and Idoit [6]. Both types of software are of course having their respective advantages and disadvantages.

For a quite large and steady company and indeed, engaged in providing services of IT, purchases a licensed software may not be too problematic. Also for companies that already make IT as an inseparable service from other services, such as banking industries, purchasing licensed software may help to transfer risks both in terms of the integration to the existing system, or in case of problems or bugs in the system occur. However, with the quite expensive cost, the new organization that will implement ITSM may be better suited to try ITSM implementation using open source software. In this study, we will focus on open source software in the new organization that will implement ITSM.

The question is how a new organization that wants to implement ITSM can choose the appropriate open source software? What criteria that are appropriately used to evaluate the ITSM software? A study tries to provide recommendations relating to the selection of ITSM open source software. Among others, conducted by [7]. The study [7] tries to evaluate 3 Free-libre Open Source Software (FLOSS) in the ITSM domain. The criteria used in the study focus on the integration between the FLOSS evaluation of the framework from [8], FLOSS implementation model literature from [9] and Risk based from [10]. From those criteria that we do not see a slice of ITIL v.3 process, whereas the software will be used for the implementation of ITSM. We therefore, try to adopt the criteria on ITIL v.3 in the evaluation process that we will create so that the selected software fits with the needs of the organization that will implement this ITSM.

Other study related to ITSM software evaluation is also conducted by [11] using Fuzzy TOPSIS approach. The criteria used by [11] include functional criteria based on ITIL v.3 and non-Functional, with a total criterion of 48. This research does not mention the software that will be evaluated, so it is difficult for an organization to assess which software is eligible to use. In addition, an approach for the organization that newly will implement ITSM, usually only limited to Service Operation. Thus, in this research we will focus on "quick win" for the implementation of ITSM in an organization, especially in the implementation of the Service Operation.

To perform the rating of those software, an Analytic Hierarchy Process (AHP) will be used. AHP is a decision-supporting model developed by Thomas L. Saaty [12] [13]. This model describes multi-factor problems or complex multi-criteria into a hierarchy defined as a multi-level structure where the first level is a goal, followed by factor level, criteria, sub-criteria, and so on downward to the last level of the alternatives.

AHP is frequent used as a troubleshooting method for rating a software [14] [15] [16] attributable to its hierarchical structure. As a consequence of the selected criteria, up to the deepest sub-criteria and consider the validity up to the limit of inconsistencies tolerance in various criteria and the alternative chosen by the decision maker.

The results of ITSM software rating created by us, are expected to contribute to the organization that newly will implement ITSM in the interest of selecting appropriate software. The author will conduct the rating of 3 ITSM software that are mostly used in accordance with the research completed by [7] includes: OTRS, iTop and IDOIT.

The paper is organized as follows: chapter 2 talks about the related work of this research. The ITSM selection criteria will be discuss on chapter 3, followed by research 
method. Chapter 5 and 6 offers the data collection, implementation and our research findings. Finally, the conclusion will be discussed on chapter 7.

\section{Related Works}

\subsection{Software Evaluation}

Research related to the rating evaluation of the software using various approaches has been widely conducted, among others, includes [14] [17] [18] [19]. The research [14] and [17] try to evaluate software for hospitals and accounting using AHP approach. AHP itself is a helpful supporting model to describe the multi-factor problems both for unclear problem structure, uncertainty of opinion from decision-maker, decision maker is more than one, and the inaccuracy of available data. To perform the evaluation, each researcher attempts to find the appropriate criteria, then based on those criteria the software will be evaluated. In this research, the used criteria more lead to the common criteria in terms of software selection, for example the availability of training and documentation, third-party support, the present of community, total line of code, ease of use, compatibility, etc.

Based on the above studies, we see that the multi-criteria model approach using AHP is very widely used for process of software evaluation and rating. Therefore, we will try to use the same method for evaluating ITSM open source software, especially for the lower and middle class organizations.

\subsection{ITSM Software Evaluation}

From the results of searching completed, we get two papers related to the evaluation of ITSM software [7] [11]. Those both papers take measurements for ITSM software, but with a different method. The research [7] using AHP approach in evaluating the 3 ITSM open source software. While, [11] using fuzzy TOPSIS. In this research, we do not try to compare the methods, but we try to see what criteria that are used by those both researches.

The research [7] using risk-based criteria that are translated into several attributes based on common criteria in terms of software evaluation and implementation. The use of risk-based is divided into four criteria, those are: financial risk, organizational risk, enduser risk and technical risk. While, some attributes used are security, documentation, quality, usefulness, functionality, usability, etc. We see that the approach of the attributes used in this research is very common. While ITSM software from the use side is indeed dedicated to support the implementation of ITIL v.3 framework. Thus, in our opinion, approaches the selection of appropriate criteria should involve existing processes in ITIL v.3.

While, the research conducted by [11] has adopted very complete criteria of ITIL v.3 wrapped in terms of functional criteria. In addition, this research also incorporates several non-functional common criteria, among other, include: quality requirements, technical requirements, vendor and implementation factors. Based on the discussion about the criteria of ITSM that will be explained in chapter III, we believe that the use of all ITIL v.3 processes in software testing criteria are not too helpful for small and medium organizations that newly will implement this ITIL v.3 framework. Usually those organizations try to use ITIL v.3 approach in service operation processes [20], such as incident, request fulfillment and problem management. As such, in this study we will focus to examine the criteria for the evaluation of ITSM open source software. To see more clearly the difference in approach to the criteria selection between the completed studies with this research, please refer to the following Table 1. 
Table 1. Criteria Comparison

\begin{tabular}{|l|c|c|c|}
\hline \multicolumn{1}{|c|}{ Criteria } & $\begin{array}{c}\text { Literature } \\
{[7]}\end{array}$ & $\begin{array}{c}\text { Literature } \\
{[11]}\end{array}$ & $\begin{array}{c}\text { Our } \\
\text { Research }\end{array}$ \\
\hline Risk based and common criteria & $\checkmark$ & & \\
\hline $\begin{array}{l}\text { All ITSM Processes and } \\
\text { common non-functional criteria }\end{array}$ & & $\checkmark$ & \\
\hline $\begin{array}{l}\text { Quick Win ITSM Process for } \\
\text { small to medium sized } \\
\text { organizations that newly will } \\
\text { implement ITIL v.3 }\end{array}$ & & & $\checkmark$ \\
\hline
\end{tabular}

\section{The ITSM Software Criteria}

ITSM criteria in this research will refer to ITIL v. 3 best practice. ITIL, on a defacto basis, is a most widely framework adopted by organizations around the world that want to implement ITSM. In addition, the use of ITIL v.3 is very compatible with standard IT Service issued by ISO, such as ISO 20000-1. Thus, organizations that implement ITIL v.3 can certainly obtain ISO 20000-1 certification [21].

In ITIL v.3 live cycle, there are five major processes, those are: Service Strategy, Service Design, Service Transition, Service Operation and Continual Service Improvement [22]. In each of those processes is also another sub process. Please refer to Figure 1 for more details.

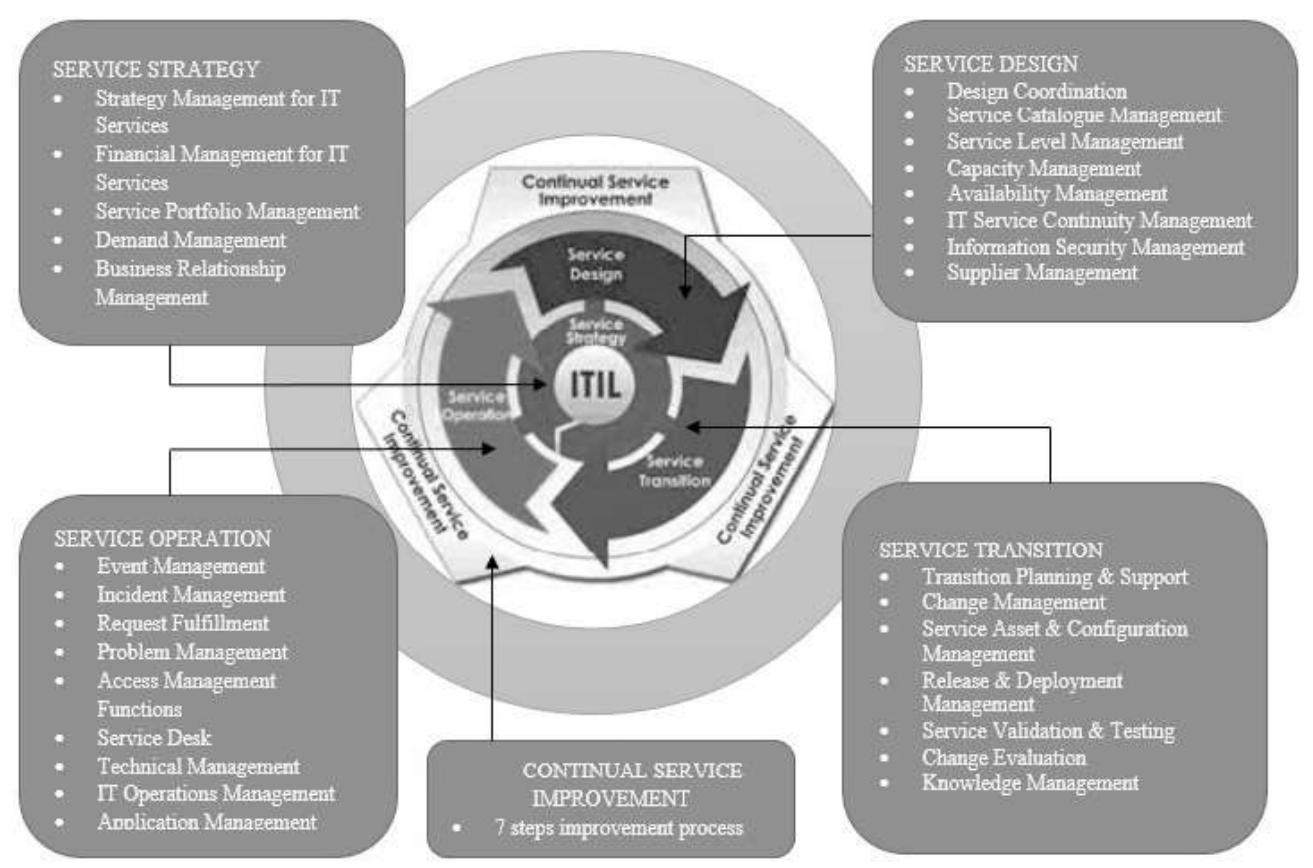

Figure 1. ITIL v.3 Processes [23]

In this research, the generated criteria will lead to processes that exist in ITIL v.3, will mainly focus on processes that exist in service operation. Approach to the criteria in service operation is selected because of many new organizations that want to implement ITSM almost all start from the Service Operation [20]. 


\subsection{Request Fulfilment}

This process aims to provide an effective and efficient channel for users who need services, and information as well. Helpdesk will serve the requests of the user in accordance with the generated catalog, in case of no user request is available in the catalog, and the helpdesk can perform an escalation into a change request process. Several metrics that exist in this process are: The number of requests found in the catalog can be completed in accordance with existing SLA.

\subsection{Incident Management}

Incident management is a governance intended to deal with an incident. Incident itself is unplanned interruption to an IT service that the interruption can decrease the quality of IT services. The purpose of incident management is to restore normal service as soon as possible, and to minimize the impact on business operations. In the incident management process, at least the function that can record, escalate and resolve the incident is required.

To measure the success of an incident handling, [24] a generated matrix can be developed into a Key Performance Indicator (KPI), among others, included: percentage of incidents handled within Service Level Agreement (SLA), the number of incidents that can be processed per-agent, the percentage of incident number assigned incorrectly.

\subsection{Problem Management}

Problem management is a process to determine the cause of unknown problem of the cause - unknown error. Incident that occurs repeatedly can be categorized as a problem. Problem management is responsible for taking precautions before the problem appears and is also responsible for conducting further investigations in case of a problem occurs. The resulted solution can be in the form of known error, which should be documented in the CMDB, or can also be a temporary solution - work around solution, i.e. a temporary so that the system runs again immediately.

Problems can be obtained from the incident recorded by the helpdesk, the present of warning of event management, reporting of application management, technical management and operation support. Following [24] we can select multiple KPIs that can be used to define the SLA, among other, include: The number of problems that can be investigated, the number of known error inserted into the CMDB.

\subsection{Event Management}

Event management process is a process used to monitor the entire event of infrastructure. This process aims to see activities that run on the infrastructure, particularly if abnormal activities are found. Prior to monitor those activities, the management should determine the threshold of activities. For example, for a threshold of memory usage on a server at $80 \%$, maximum CPU use is $80 \%$ and maximum storage use is $85 \%$. So, if there are events that pass the threshold, then the agent embedded in the infrastructure will send alert into the existing software system. The alert can go to the incident and or problem category.

\subsection{Access Management}

Access management is used to give the user rights for access to the service, while preventing access to non-authorized user.

Of the criteria exist in the Service Operation above, we only use four processes in this research, those are: request fulfillment, incident management, problem management, and event management. We issue the access management in the process of ITSM software rating because we see that three software that will be evaluated not give specific access 
management in the existing modules. It aims to avoid comparison that no apple to apple is present.

\section{Research Method}

\subsection{Collecting Data}

In evaluating ITSM software, we conduct interviews to some ITIL v.3's expert users. The purpose of these interviews is to gain appropriate description about ITSM software which will be ranked using AHP method. Information from interview is needed to strengthen the evaluation result.

Not only by interview, the ITIL v.3's users are also filled out questionnaire for each ITSM software. This questionnaire will be used to form criteria matrix.

\subsection{Modelling Problem}

In this stage, we made a model of problem using AHP method. Analytic Hierarchy Process (AHP) was developed by Thomas L.Saaty in the 70s. AHP is a method that can be used in the decision support system or decision-making system by taking into account the factors of perception, preferences, experience and intuition. AHP incorporates judgments and personal values into a single logical way [25].

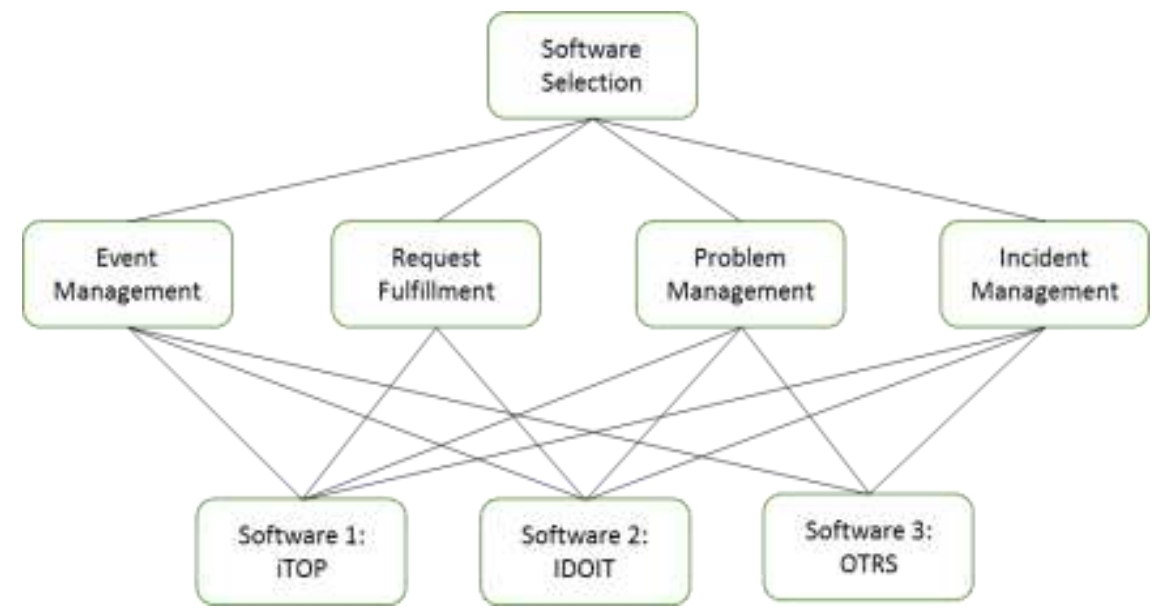

Figure 2. Decision Hierarchy

In this research, several stages should be followed:

1. Structure the decision hierarchy

The structure the decision hierarchy that represents the goal and decision, and their relationship. In this hierarchy of decision there are objective, criteria and alternatives. It is clearly defined that the goal which will be discussed in this study is about ITSM software selection based on ITIL V.3's criteria. At Figure 2 can also be seen that criteria used are the processes which exist in ITIL v.3, especially focusing on the process in the service operation: Event Management, Incident management, Problem Management and Request Management. These criteria will be processed later to choose alternative solutions, where alternative solutions to the problem are three types of ITSM software, namely: OTRS, iTop and IDOIT.

2. Provide assessment of alternatives decision.

For this research, ITIL v.3's users determine the value of alternatives using scale 1-5 which formed based on AHP's fundamental scale.

3. Forming pairwise comparison of various criteria as generated at step 2 into a matrix.

4. Calculate the eigenvalue of these matrix

5. Calculate Consistency Index (CI) and Consistency Ratio (CR) 
6. Calculate the rank of alternatives.

Flow of this research can be seen in Error! Reference source not found.

\section{Data Collection}

From the data collection phase the followings data were obtained:

1. AHP weighting scale for ITSM software evaluation.

In this research, AHP's fundamental defined by Saaty [12] [13] was converted into a likert scale of 1-5. This 1-5 scale was generated to make respondents easy to fill out questionnaire in which each value scale was a representation of ITSM software use. This value will be used by ITIL's user in filling out the questionnaire. The details of converted scale can be seen in Table 2 .

Table 2. Score of ITSM Software Evaluation

\begin{tabular}{|c|c|l|}
\hline Score & Remarks & \multicolumn{1}{c|}{ Description } \\
\hline 5 & Excellent & $\begin{array}{l}\text { 1. User can use it easily. } \\
\text { 2. The request process can be carried out by external or } \\
\text { service desk. } \\
\text { 3. Able to manage incident (minimize adverse impact). } \\
\text { 4. Able to diagnose the cause of the incident. } \\
\text { 5. Able to provide the request of service from users }\end{array}$ \\
\hline 4 & Very Good & $\begin{array}{l}\text { 1. Processing is good, due to detailed and complex. } \\
\text { 2. There is a process of escalation. }\end{array}$ \\
\hline 3 & Good & $\begin{array}{l}\text { 1. Able to provide and verify incident that happens. } \\
\text { 2. Necessary arrangement, making it rather difficult for } \\
\text { the user. }\end{array}$ \\
\hline 2 & Fair & $\begin{array}{l}\text { 1. Explain no relationship between the events that occur } \\
\text { in the software infrastructure. } \\
\text { 2. Unable to detect incidents or instruction (notification). } \\
\text { 1. Unable to minimize the adverse impact that will occur. } \\
\text { 2. Unable to prevent when the incident occurred. } \\
\text { 3. Unable to provide a standard of service to users. } \\
\text { 4. Lack of available features and tools }\end{array}$ \\
\hline 1 & Poor &
\end{tabular}

2. Results of interview and questionnaire from ITIL v.3 users

To calculate the rating using AHP, we needed weight for each criteria, in this case the ITSM software service operation, specifically event management, incident management, problem management and request management. Some ITIL v.3 users filled out questionnaire which has been prepared for the research. It was a simple questionnaire, with 5-likert scale to rate the statement.

Purposive sampling method was used in selecting some respondents to be participated in filling out the questionnaire. In purposive sampling method, only limited numbers of people can serve as primary data sources due to the nature of research design and aims and objectives. Therefore in this research, in order to get good quality of questionnaire data, the respondents should be the one with good capability in IT service management and experienced as ITIL v.3 user.

We need to ensure that the data obtained were good enough to be proceed so the consistency value of the data had to be checked first. The data was said to be feasible to be used in calculation if it had CI value less than 0.1. The example of CI calculation can be found in Table 8 . 


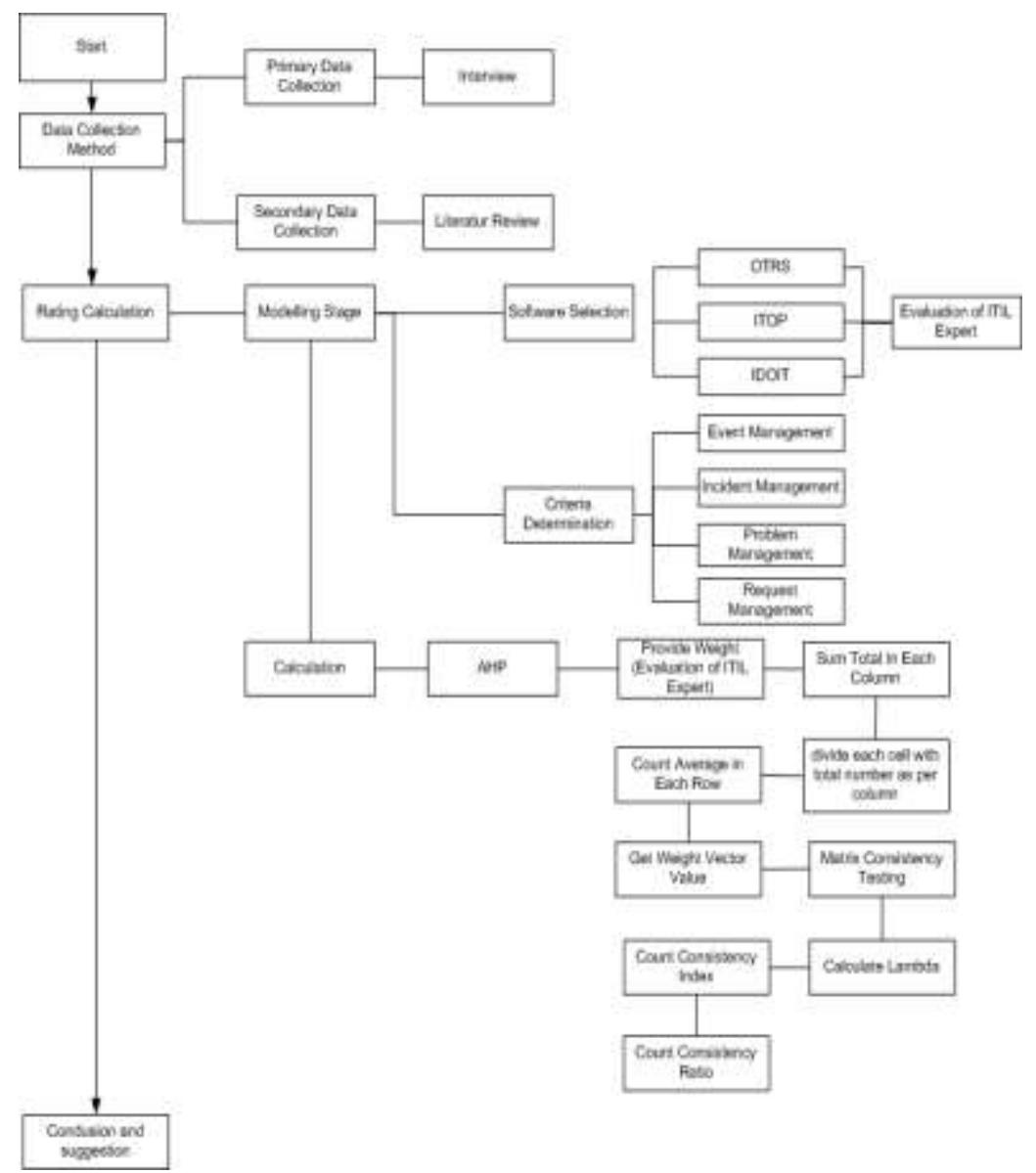

Figure 3. Research Process Flow Chart

\section{Software Evaluation}

The steps of AHP process are described as below:

a. Provision of Weight

Provision of weight was the first step of AHP process. Provision of weight carried on each of the criteria to form a pairwise comparison matrix. (Table 3).

Table 3. Provision of Event Management Weight

\begin{tabular}{|c|c|c|c|}
\hline Criteria & OTRS & iTop & IDOIT \\
\hline OTRS & $1 / 1$ & 1.2 & $4 / 1$ \\
\hline iTop & $2 / 1$ & $1 / 1$ & $3 / 1$ \\
\hline IDOIT & $1 / 4$ & $1 / 3$ & $1 / 1$ \\
\hline
\end{tabular}

b. Result of Normalization

The next step was to calculate the value of a weight vector. Value for weight vector for event management is $\mathrm{W}=\{0.36 ; 0.51 ; 0.13\}$. The result was shown in Table 4 . 
Table 4. Event Management Normalization

\begin{tabular}{|c|c|c|c|c|}
\hline Criteria & OTRS & iTop & IDOIT & Result \\
\hline OTRS & 0.31 & 0.27 & 0.50 & 0.36 \\
\hline iTop & 0.62 & 0.55 & 0.38 & 0.51 \\
\hline IDOIT & 0.08 & 0.18 & 0.13 & 0.13 \\
\hline
\end{tabular}

c. Consistency Testing

Further testing for consistency matrix was conducted. A was a pairwise comparison matrix, and $\mathrm{W}$ was the weight vector value (Table)

Table 5. Consistency Testing

\begin{tabular}{|l|c|c|}
\hline \multirow{3}{*}{$(A)\left(W^{T}\right)$} & Matrix Consistency Testing & Result \\
\cline { 2 - 3 } & {$\left[\begin{array}{lll}0.31 & 0.27 & 0.50 \\
0.62 & 0.55 & 0.38 \\
0.08 & 0.18 & 0.13\end{array}\right]\left[\begin{array}{l}0.36 \\
0.51 \\
0.13\end{array}\right]$} & 11.13 \\
\cline { 3 - 3 } & & 11.62 \\
\cline { 3 - 3 } & & 00.39 \\
\hline
\end{tabular}

\section{d. Calculating CI And CR}

Before calculating the value of CI, a lambda value calculation was required, which was obtained by dividing the results of matrix consistency testing with results of normalization and then divided by the number of existing criteria.

Table 6. Calculating Lambda

\begin{tabular}{|c|c|}
\hline Formula & Result \\
\hline$t=\frac{1}{n} \sum_{i=1}^{n}\left(\frac{\left(\text { element on }-i \text { in }(A)\left(W^{T}\right)\right.}{\text { element on }-i \text { in } W^{T}}\right)$ & 3.11 \\
& \\
\hline
\end{tabular}

CI value was obtained from the subtraction of the value criteria. After CI value was obtained, an index ratio value was calculated, which was the average of CI value.

\section{Table 7. Calculating Consistency Index}

\begin{tabular}{|c|c|}
\hline Formula & Result \\
\hline$C I=\frac{t-n}{n-1}$ & 0.054326 \\
\hline
\end{tabular}

After obtaining CI value, a CR value was calculated. This stage was the last stage of AHP process. The results obtained at this stage was obtained by dividing the results of index consistency with the index ratio.

The same process was also performed for Incident Management, Problem Management, and Request Management. 
Table 8. Consistency Ratio Checking

\begin{tabular}{|c|c|c|c|}
\hline Formula & $\begin{array}{c}\text { Calculation } \\
\text { Formula }\end{array}$ & Result & Remarks \\
\hline$C R=\frac{C I}{R I_{3}}$ & $\frac{C I}{R I_{3}}=\frac{0.054326}{0.58}$ & 0.093665 & $\begin{array}{c}\text { Consistent } \\
(\leq 0.1)\end{array}$ \\
\hline
\end{tabular}

\section{ITSM Software Ranking}

To perform the rating, the priority vector of each criteria was multiplied with weight based on Software Operation. The priority vector value can be seen in Table 9 and the result of multiplication is in Table 10 .

Table 9. Priority Vector

\begin{tabular}{|c|c|c|c|c|}
\hline \multicolumn{5}{|c|}{ Priority Vector } \\
\hline $\begin{array}{c}\text { Event } \\
\text { Managemen } \\
\mathrm{t}\end{array}$ & $\begin{array}{c}\text { Incident } \\
\text { Managemen } \\
\mathrm{t}\end{array}$ & $\begin{array}{c}\text { Problem } \\
\text { Managemen } \\
\mathrm{t}\end{array}$ & $\begin{array}{c}\text { Request } \\
\text { Managemen } \\
\mathrm{t}\end{array}$ & Software \\
\hline 0.36 & 0.15 & 0.15 & 0.16 & 0.10 \\
\hline 0.51 & 0.70 & 0.70 & 0.69 & 0.34 \\
& 0.15 & 0.15 & 0.15 & 0.14 \\
& & & & 0.42 \\
\hline
\end{tabular}

Table 10. Matrix Calculation

\begin{tabular}{|c|l|l|}
\hline Multiplication & OTRS & 0.17 \\
\cline { 2 - 3 } Results & iTop & 0.68 \\
\cline { 2 - 3 } & IDOIT & 0.15 \\
\hline
\end{tabular}

The result of calculation (Table 10) is said to be global priority rating, which showed the rating value of the ITSM software. Table 11 showed the alternative of ITSM software selection and its global priority, with iTop in the first rank with value of 0.68 , followed by OTRS at second rank with value of 0.17 , and IDOIT ranks the third position with value of 0.15 .

Table 11. Global Priority

\begin{tabular}{|l|c|}
\hline \multicolumn{1}{|c|}{ Alternative } & Global Priority \\
\hline OTRS & 0.17 \\
\hline iTop & 0.68 \\
\hline IDOIT & 0.15 \\
\hline
\end{tabular}




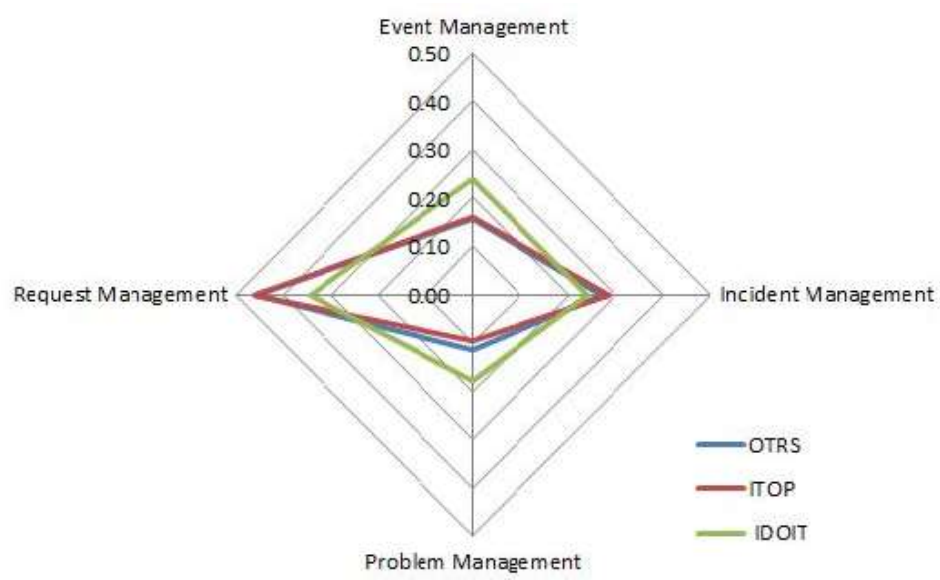

Figure 4. Kivait for Service Operation Assessment

\section{Summary and Future Work}

On a functional basis, an analysis of ITSM Software Using AHP based on ITIL v.3 Service Operation produced the expected output that was able to provide an assessment of ITSM software performance among others, includes OTRS, iTop and IDOIT. Criteria selection for ITIL v.3 Service Operation conducted to help small and medium-sized organizations that newly will implement ITSM with ITIL v.4 framework.

Based on this research, it can be seen that under AHP (Analytical Hierarchy Process), iTop software quality was the most excellent of other software. Because it has the most excellent global priority, namely 0.68 . Then sequential of OTRS and IDOIT.

In further research, it is expected to conduct a research on the assessment of ITSM Software performance with the selection of "quick win" criteria for the implementation of ITSM, so there should not be a thorough evaluation process, but is not also limited to Service Operation. Thus, it is expected that small and medium-sized organizations that will implement ITSM get more comprehensive recommendations related to selection of open source software to be used.

\section{References}

[1] M. Mora, M. Raisinghani, R. V. O'Connor, J. M. Gomez and O. Gelman, "An Extensive Review of IT Service Design in Seven International ITSM Process Framework: Part I," International Journal of Information Technologies and Systems Approach, vol. 7, no. 2, (2014), pp. 83-107.

[2] J. I. a. T. R. Eikebrokk, "Implementing IT Service Management: A Systematic Literature Review," International Journal of Information Management, vol. 33, no. 3, (2013), pp. 512-523.

[3] K. Kanapathy and K. I. Khan, "Assessing The Relationship between ITIL Implementation Progress and Firm Size: Evidence from Malaysia," International Journal of Business and Management, vol. 7, no. 2, (2012), pp. 194-199.

[4] S. M. Nelima, "Information Technology Infrastructure Library (ITIL) Adoption and Its Effect on Organizational Performance - A Survey of Listed Firms on The Nairobi Securities Exchange," Univesity of Nairobi, Nairobi, (2013).

[5] anonymous, "Reviews for IT Service Support Management Tools," Gartner, [Online]. Available: https://www.gartner.com/reviews/market/itssm-tools, (2016). [Accessed 1611 2016].

[6] E. Blum, "6 Best Service Desk Open Source solutions," 1703 2016. [Online]. Available: http://www.itsmdaily.com/best-service-desk-open-source-solutions, (2016). [Accessed 1611 2016].

[7] M. Mora, J. M. Gomez, R. O'Connor and O. Gelman, "A Risk-based MADM Model for Selecting FreeLibre Open Source," Proceedings of the 14th Symposium on Decision Technology and Intelligent Information Systems, Germany, (2015).

[8] D. Nagy, A. Yassin and A. Bhattacherjee, "Organizational Adoption of Open Source," Communications of the ACM, vol. 53, no. 3, (2010), pp. 148-151.

[9] J. Dedrick and J. West, "Why Firms adopt Open Source Platforms: a Grounded Theory of," in MISQ Special Issue Workshop, (2003). 
[10] G. Stoneburne, A. Goguen and A. Feringa, "Risk Management Guide for Information," National Institute of Standards and Technology, (2002).

[11] S. Rouhani and A. Z. Ravasan, "A Fuzzy TOPSIS based Approach for ITSM Software Selection," International Journal of IT/Business Alighment and Governance, vol. 5, no. 2, (2014), pp.1- 26.

[12] T. L. Saaty, "What Is The Analytic Hierarchy Process?," In Mathematical Models for Decision Support, (1988), pp. 109-12.

[13] T. L. Saaty, "How to Make A Decision: The Analytic Hierarchy Process.," European Journal of Operational Research, vol. 48, no. 1, (1990), pp. 9-26.

[14] H. Ahmadi, M. S. Rad, M. Nazari, M. Nilashi and O. Ibrahim, "Evaluating the Factors Affecting the Implementation of Hospital Information System (HIS) Using AHP," Life Science Journal, vol. 11, no. 3, (2014), pp. 202-207

[15] S. K. Garg , S. Versteeg and R. Buyya, "A Framework for Ranking of Cloud Computing Services," Future Generation Computer Systems, vol. 29, no. 4, (2013), pp. 1012-1023.

[16] Y. Zhang , X. Deng, D. Wei and Y. Deng, "Assessment of E-Commerce Security using AHP and Evidential Reasoning," Expert Systems with Applications, vol. 39, (2012), pp. 3611-3623.

[17] W. Ossadnik and R. Kaspar, "Evaluation of AHP software from a management accounting perspective," Journal of Modelling in Management, vol. 8, no. 3, (2013), pp. 305-319.

[18] C. Blattert, R. Lemm and O. Thees, "Evaluation of Growth Simulators for Forest Management in Terms of Functionality and Software Structure Using AHP," in Applications and Theory of Analytic Hierarchy Process - Decision Making for Strategic Decisions, InTech, (2016).

[19] Z. Ayağ, "CAD Software Evaluation for Product Design to Exchange Data in a Supply Chain Network," Int. J Sup. Chain. Mgt, vol. 4, no. 1, (2015), pp. 30-38.

[20] C. Gary, "ITIL V3: Where To Start \& How To Achieve Quick Wins," Pink Elephant, (2007).

[21] T. Anel and F. Orucevic, "Improvement of Implementation of ISO/IEC 20000 Edition 2 standard in IT Systems of Telecom Operatpr Through Comparison with ITIL V3 Best Practice," in 1st WSEAS International Conference on Information Technology and Computer Networks, (2012), pp.333-337

[22] Office of Government Commerce, The Official Introduction to the ITIL Service Lifecycle, The Stationery Office, London, (2007).

[23] P. Bernard, IT Service Management Based on ITIL 2011 Edition, Van Haren Publishing, Zaltbommel, (2014).

[24] Anonymous, Service Operation, The Stationery Office, London, (2007).

[25] Kusumadewi, S. Hartati, A. Harjoko and R. Wardoyo, Fuzzy Multi - Attribute Decision Making (Fuzzy MADM), Graha Ilmu, Yogyakarta, (2006)
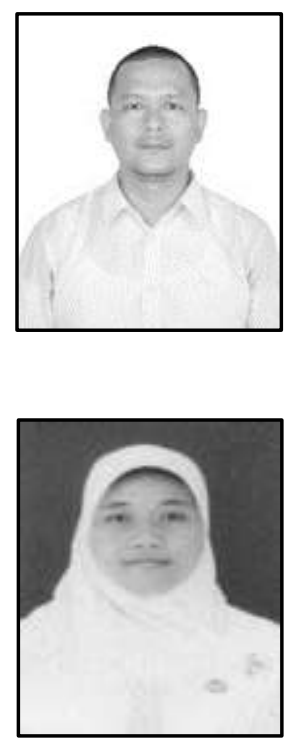

\section{Authors}

Husni Teja Sukmana, Affiliation: Syarif Hidayatullah State Islamic University Jakarta, Email: husniteja@uinjkt.ac.id, Research Area: Embedded System, IT Service Management, Virtual Machine, History: 2006-2009 Sun Moon University, Computer Science and Engineering (Doctor Degree), 2001-Now Lecture at Department of Informatics Engineering, Syarif Hidayatulah State Islamic University Jakarta

Luh Kesuma Wardhani, Affiliation: Syarif Hidayatullah State Islamic University Jakarta, Email: luhkesuma@uinjkt.ac.id, Research Area: machine learning, fuzzy logic, neural network, Decision support system, ITSM, History: 2004 - 2006 ITB, informatics (master degree), 2015-Now Lecture at Department of Informatics Engineering, Syarif Hidayatulah State Islamic University Jakarta 


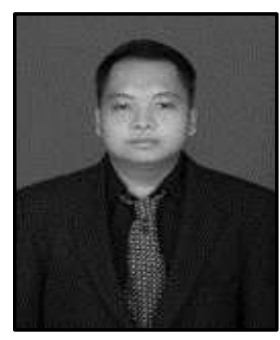

Roni Argantone Maulana, Affiliation: Syarif Hidayatullah State Islamic University Jakarta, Email: roniargantone@mhs.uinjkt.ac.id, Research Area: IT Service Management, Decision Support System, History: 2012-2017 Syarif Hidayatulah State Islamic University Jakarta, Informatics Engineering (Bachelor of Computer Science) 
International Journal of Control and Automation Vol.10, No.7 (2017) 